\title{
An Analytical Investigation on Behavior of Cross (+) Shaped RC Columns Using $\mathrm{P}_{\mathrm{U}}-\mathrm{M}_{\mathrm{U}}$ Interaction Diagrams
}

\author{
Shanmukha Shetty, R.M. Subrahmanya, B.G. Naresh Kumar and H.S. Narashimhan
}

\begin{abstract}
The design aid for reinforced concrete to IS 456-1978, provides $P$-M interaction diagrams as a design aid to simplify the design of rectangular and circular columns. As these two sections are symmetric, it becomes comparatively easy to provide the respective interaction diagrams, whereas the same is difficult for nonconventional sections like flanged and tubular cross sections. In this work an effort has been put forth in this area to develop interaction diagram for cross(+) shaped columns by varying some of its parameters such as spacing of reinforcement, grade of concrete and steel, the results showed that with the increase in grade of material there was a considerable increase in load and moment carrying capacity of the column, also by varying the spacing higher strength could be achieved in comparison with equally spaced section for a given percentage of steel.
\end{abstract}

Keywords--- $P_{U}-M_{U}$ Interaction Diagram, Cross (+) Shaped RC Columns, Behavioral Analysis

\section{INTRODUCTION}

$\mathrm{T}$ HE design of reinforced concrete columns is a tedious, time consuming, and iterative procedure, to simplify the design procedure SP-16 has provided non dimensional interaction diagrams for various $\mathrm{d}$ '/D ratio and percentage of steel. And SP-16 has also specified the procedure to develop interaction diagrams for any type of column with various specifications.

An interaction diagram could be drawn for a column with given specifications such as grade, percentage of steel, reinforcement detailing pattern, dimension and shape of column by evaluating strain at various locations in the column considered, there by evaluating stress which intern provides load and moment values, such numerous values of ultimate load and moment resisting capacity could be evaluated at various locations once the set of ultimate load and moment resistance values are obtained it could be graphically represented as an interaction diagram which serves as a failure envelop implying that any combination of load and moment that falls within the envelop is safe with the load-moment

Shanmukha Shetty, Department of Civil Engineering, MCE Hassan. E-mail:shanmukha022@rediffmail.com

R.M. Subrahmanya, Assistant Professor, Department of Civil Engineering, VCET Puttur. Mysore.

B.G. Naresh Kumar, Prof., Principal, Maharaja Institute of Technology,

H.S. Narashimhan, Associate Professor, Department of Civil Engineering, MCE Hassan.

DOI:10.9756/BIJMMI.8162 combination that falls on the envelop as the maximum load-moment resisting capacity of the section. Therefore interaction diagrams are of paramount importance in design of columns.

\section{SCOPE AND SIGNIFICANCE OF THE RESEARCH WORK}

RC columns are usually subjected to axial loads in combination with bending in uni-axial or bi-axial directions for all practical cases, therefore the column rather than behaving as a pure compression member, behaves as abeam-column.SP-16:" Design aid for reinforced concrete to IS 456-1978" has provided various interaction diagrams for conventional column sections only and not for specially shaped sections, and there is a lack of information on the behavioral description of such specially shaped columns in terms of interaction diagrams in the code, therefore the present study is an attempt to develop interaction diagrams for one of the specially shaped RC columns i.e. cross (+) shaped columns, and study the influence of varying grade of material and reinforcement spacing on strength characteristics of cross (+) shaped columns, in course of the work a spread sheet has been developed using Microsoft excel which could supply interaction diagrams for cross (+) shaped, L-shaped, T-shaped, and rectangular columns with a provision to vary all specifications such as grade of concrete and steel, reinforcement spacing etc...these interaction diagrams would considerably makes the design process simpler and quicker.

\section{INTERACTION DIAGRAMS}

The interaction curve for a column is a graphical representation of design strength of columns subjected to uniaxial eccentricity for the given specifications. Axial load versus moment interaction diagram can be used for the design of eccentrically loaded columns, an interaction curve can be plotted by evaluating various axial load and moment combinations obtained for various positions of neutral axis.

Any point on the interaction curve has its co-ordinates as the ultimate load $\mathrm{P}_{\mathrm{UR}}$ and ultimate moment $\mathrm{M}_{\mathrm{UR}}$ as the maximum combination of load and moment that could be resisted by the column corresponding to a particular value of eccentricity, the line joining the origin ' $O$ ' to any point on the curve is called as the loading line, and reciprocal of slope of this line is called as eccentricity ' $e$ ' as shown in figure 


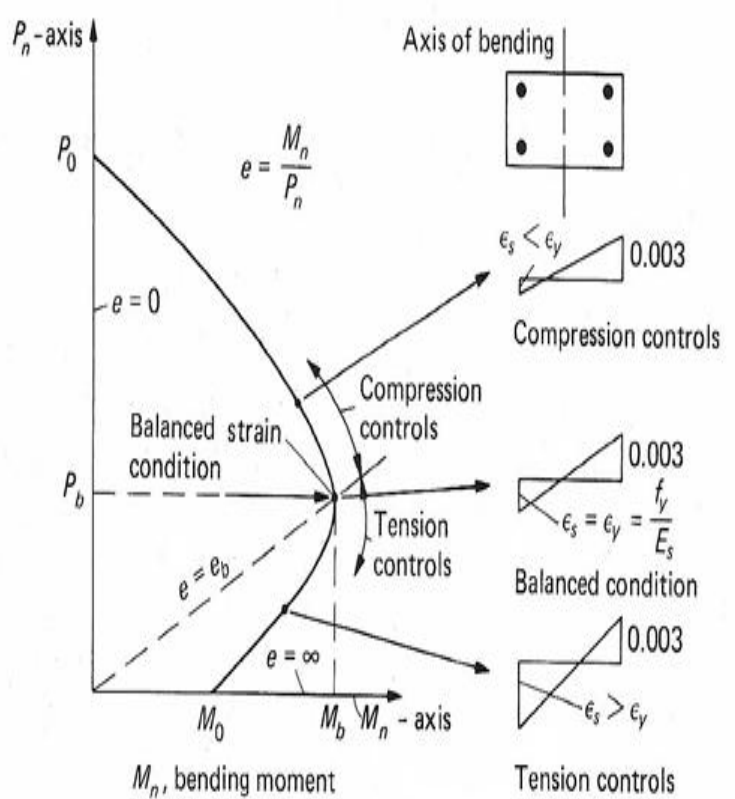

Figure 1: Typical Interaction Diagram

Interaction diagrams have two fold application, these diagrams could be used to assess the strength of a given column, on the other hand they could be effectively used to design a column to support a particular combination of external load and moment.

To develop interaction diagram, neutral axis will be assumed to be located at various positions and load and moment capacity corresponding to particular position of neutral axis were evaluated then the algebraic sum of load carrying capacity of steel and that of concrete gives the total axial load carrying capacity of the column, on similar lines total moment carrying capacity will also be calculated.

\section{METHODOLOGY}

To proceed with first various locations of neutral axis were assumed and the capacity of column to carry the load and moment were evaluated for a particular location of neutral axis, as this procedure is repeated for various locations of neutral axis it is iterative, the procedure involves following steps.

\section{A. For the Case of Neutral Axis Situated Within the Section}

- $\quad \mathrm{P}_{\mathrm{uc}}=$ Capacity of concrete to carry axial load $=0.361$

$$
\mathrm{Xf}_{\text {ck }} \text { X B X Xumax }
$$

Where,

$\mathrm{f}_{\mathrm{ck}}=$ Characteristic compressive strength of concrete in $\mathrm{N} / \mathrm{mm}^{2}$

$\mathrm{B}=$ Width of the section in $\mathrm{mm}$ Xumax $=$ Depth of the NA from highly compressed edge in $\mathrm{mm}$

- Strain in steel/concrete

Where,

$$
\left(\varepsilon_{\mathrm{c}}\right)=0.0035 \mathrm{X} \frac{\text { Xumax }-\mathrm{d}_{\mathrm{i}}^{\prime}}{\text { Xumax }}
$$

$\mathrm{d}_{\mathrm{i}}^{\prime}=$ distance of $\mathrm{i}^{\text {th }}$ row of reinforcement from highly compressed edge

- $\quad$ Stress in steel $\left(\mathrm{f}_{\mathrm{sc}}\right)$
Stress in steel can be evaluated by using Table 1, interpolation may be done for intermediate values.

Table 1: Values of Design Stress-Strain Curve for Hysd Bars

\begin{tabular}{|c|c|c|c|c|}
\hline \multirow{2}{*}{ Stress Level } & \multicolumn{2}{|c|}{$f_{\mathrm{y}}=415 \mathrm{~N} / \mathrm{mm}^{2}$} & \multicolumn{2}{c|}{$f_{\mathrm{y}}=500 \mathrm{~N} / \mathrm{mm}^{2}$} \\
\cline { 2 - 5 } & Strain & Stress N/mm & Strain & Stress $\mathrm{N} / \mathrm{mm}^{2}$ \\
\hline $0.80 \mathrm{f}_{\mathrm{yd}}$ & 0.00144 & 288.7 & 0.00174 & 347.8 \\
\hline $0.85 \mathrm{f}_{\mathrm{yd}}$ & 0.00163 & 306.7 & 0.00195 & 369.6 \\
\hline $0.90 \mathrm{f}_{\mathrm{yd}}$ & 0.00192 & 324.8 & 0.00226 & 391.3 \\
\hline $0.95 \mathrm{f}_{\mathrm{yd}}$ & 0.00241 & 342.8 & 0.00277 & 413.0 \\
\hline $0.975 \mathrm{f}_{\mathrm{yd}}$ & 0.00276 & 351.8 & 0.00312 & 423.9 \\
\hline $1.0 \mathrm{f}_{\mathrm{yd}}$ & 0.00380 & 360.9 & 0.00417 & 434.8 \\
\hline
\end{tabular}

- Stress in concrete $\left(\mathrm{f}_{\mathrm{cc}}\right)$

When, $\varepsilon_{\mathrm{c}} \geq 0.002$,

When, $\varepsilon_{\mathrm{c}}<0.002$,

$$
\mathrm{f}_{\mathrm{sc}}=0.446 \mathrm{Xf}_{\mathrm{ck}}
$$

$$
\mathrm{f}_{\mathrm{sc}}=446 \mathrm{Xf}_{\mathrm{ck}} \mathrm{X} \varepsilon_{\mathrm{c}} \mathrm{X}\left[1-\left(250 \mathrm{X} \varepsilon_{\mathrm{c}}\right)\right]
$$

- Total load carrying capacity of column $(\mathrm{Pu})$ $=0.361 \mathrm{X} \mathrm{f}_{\mathrm{ck}} \mathrm{X} \mathrm{B} \mathrm{X} \mathrm{D}+\Sigma$ [Ast X (Stress in steel Stress in concrete)]

- Capacity of concrete to carry moment

$(\mathrm{Muc})=0.361 \mathrm{Xf}_{\mathrm{ck}} \mathrm{X}$ B X Xumax X $[\mathrm{C} . \mathrm{G}-(0.416 \mathrm{X}$ Xumax)]

Where,

C.G $=$ Centre of gravity from highly compressed edge

- Total moment carrying capacity of column

$(\mathrm{Mu})=0.361 \mathrm{X}_{\mathrm{ck}} \mathrm{X}$ B X Xumax X [C.G $-(0.416$ X Xumax $)]+\Sigma[$ Ast $X($ Stress in

steel - Stress in concrete) $X$ lever arm distance]

Lever arm distance $=\left(C . G-d_{\mathrm{i}}^{\prime}\right)$

B. For the Case of Neutral Axis Situated Outside the Section

- Capacity of concrete to carry axial load $\left(\mathrm{P}_{\mathrm{UC}}\right)$

$$
\mathrm{P}_{\mathrm{UC}}=\mathrm{C}^{\prime} 1 \mathrm{X} \text { fck X B X Xumax }
$$

Where,

fck $=$ Characteristic compressive strength of concrete in $\mathrm{N} / \mathrm{mm} 2$

$\mathrm{B}=$ Width of the section in $\mathrm{mm}$

Xumax $=$ Depth of the NA from highly compressed edge in $\mathrm{mm}$

C'1 = Stress block parameter corresponding to area of stress block

- $\quad$ Strain in steel/concrete ( $\varepsilon c)$

Where,

$$
\varepsilon \mathrm{c}=\varepsilon_{\mathrm{cu}} X \frac{\text { Xumax }-\mathrm{d}_{\mathrm{i}}^{\prime}}{\operatorname{Xumax}}
$$

$\varepsilon \mathrm{cu}=$ Ultimate strain $=0.0035-0.75 \mathrm{X}$ عmin

emin is evaluated as

$$
\frac{0.0035-0.75 \times \varepsilon_{\min }}{(\mathrm{D}+(\mathrm{K}-1) \mathrm{D})}=\frac{\varepsilon_{\min }}{(\mathrm{K}-1) \mathrm{D}}
$$

- Stress in steel (fsc) using table 3.1

- Stress in concrete (fcc)

When, $\varepsilon c>0.002$,

$$
\mathrm{fsc}=0.446 \mathrm{X} \mathrm{fck}
$$

When, $\varepsilon c<0.002$,

$$
\text { fsc }=446 \text { X fck X } \varepsilon c \text { X }[1-(250 X \varepsilon c)]
$$

- Total load carrying capacity of column $(\mathrm{Pu})$

$\mathrm{P}_{\mathrm{U}}=\mathrm{C}_{1}{ }^{\prime} \mathrm{X}$ fck X B X D $+\Sigma$ [Ast X (Stress in steel Stress in concrete)]

- $\quad$ Capacity of concrete to carry moment (Muc) 
$\mathrm{M}_{\mathrm{UC}}=\mathrm{C}_{1}{ }^{\prime} \mathrm{X}$ fck X B X Xumax X [C.G $-\left(\mathrm{C}_{2}{ }^{\prime} \mathrm{X}\right.$ Xumax)]

Where,

C.G $=$ Centre of gravity from highly compressed edge $\mathrm{C}_{2}{ }^{\prime}=$ Coefficient corresponding to centroidal distance of the stress block from highly compressed edge

- Total moment carrying capacity of column $\left(\mathrm{M}_{\mathrm{U}}\right)$ $\mathrm{M}_{\mathrm{U}}=\mathrm{C} 1^{\prime} \mathrm{X}$ fck X B X Xumax X [C.G - $\left(\mathrm{C}_{2}{ }^{\prime} \mathrm{X}\right.$ Xumax $)]+\Sigma[$ Ast $\mathrm{X}$ (Stress in steel - Stress in concrete) $\mathrm{X}$ lever arm distance]

$$
\text { Lever arm distance }=\left(C . G-d_{i}^{\prime}\right)
$$

Table 2: Stress Block Parameters for NA Situated Outside the Section

\begin{tabular}{|l|c|c|}
\hline$k=\frac{X_{u}}{D}$ & Coefficient $C_{l}{ }^{\prime}=\frac{C_{c}}{f_{c k} \times B \times D}$ & $\begin{array}{l}\text { Coefficient } \\
C_{2}{ }^{\prime}=\frac{Y_{c}}{f_{c k} \times B \times D}\end{array}$ \\
\hline 1.0 & 0.361 & $\mathrm{y}$ \\
\hline 1.05 & 0.374 & 0.432 \\
\hline 1.1 & 0.384 & 0.443 \\
\hline 1.2 & 0.399 & 0.458 \\
\hline 1.3 & 0.409 & 0.468 \\
\hline 1.4 & 0.417 & 0.475 \\
\hline 1.5 & 0.422 & 0.480 \\
\hline 2.0 & 0.435 & 0.491 \\
\hline 2.5 & 0.44 & 0.495 \\
\hline 3.0 & 0.442 & 0.497 \\
\hline 4.0 & 0.444 & 0.499 \\
\hline
\end{tabular}

C. For the Case of Neutral Axis Situated at Infinity (eccentricity $=0$ )

$$
\mathrm{P}_{\mathrm{u}}=0.446 \mathrm{Xf}_{\mathrm{ck}} \mathrm{X} \mathrm{A}_{\mathrm{C}}+\mathrm{f}_{\mathrm{s}} \mathrm{X} \mathrm{A}_{\mathrm{sc}}
$$

Where, $A_{c}=$ Area of concrete

$f_{s}=0.79 \mathrm{X} \mathrm{f}_{\mathrm{y}}$ for $\mathrm{Fe} 415$ grade of steel

$\mathrm{f}_{\mathrm{s}}=0.75 \mathrm{X} \mathrm{f}_{\mathrm{y}}$ for Fe 500 grade of steel

$\mathrm{A}_{\mathrm{sc}}=$ Area of compressive steel

\section{RESUltS AND DISCUSSION}

In the present work interaction diagrams for cross (+) shaped columns were developed using the spread sheet, which could give interaction diagrams for cross(+) shaped, L shaped, T-shaped, and rectangular section, the spread sheet developed will also have the provisions of modifying the grades of materials, spacing of reinforcement, size of the section et..., the interaction diagrams were developed based on the method suggested in SP:16, and IS : 456-2000, as described in the methodology in this paper, neutral axis positions were considered at various levels of the section and even outside the section for $\mathrm{K}>1$, as shown in table 2, and the

Values of $\mathrm{P}_{U}$ and $\mathrm{M}_{U}$ were obtained, the neutral axis positions were considered between the rows of reinforcement also to get a smooth, accurate and complete interaction diagram for the considered cross (+) shaped column.

Also the effect of varying grade of concrete and steel were studied by developing interaction diagrams for M20, M25, M30, M35, M40 grades of concrete with Fe415 and Fe500 grade steel, also a study has been carried out to establish the influence of varying spacing of reinforcement in comparison with constant spacing using interaction diagrams, the results were presented and discussed in this section.

\section{A. Influence of Grade of Concrete with Fe 415 Grade Steel}

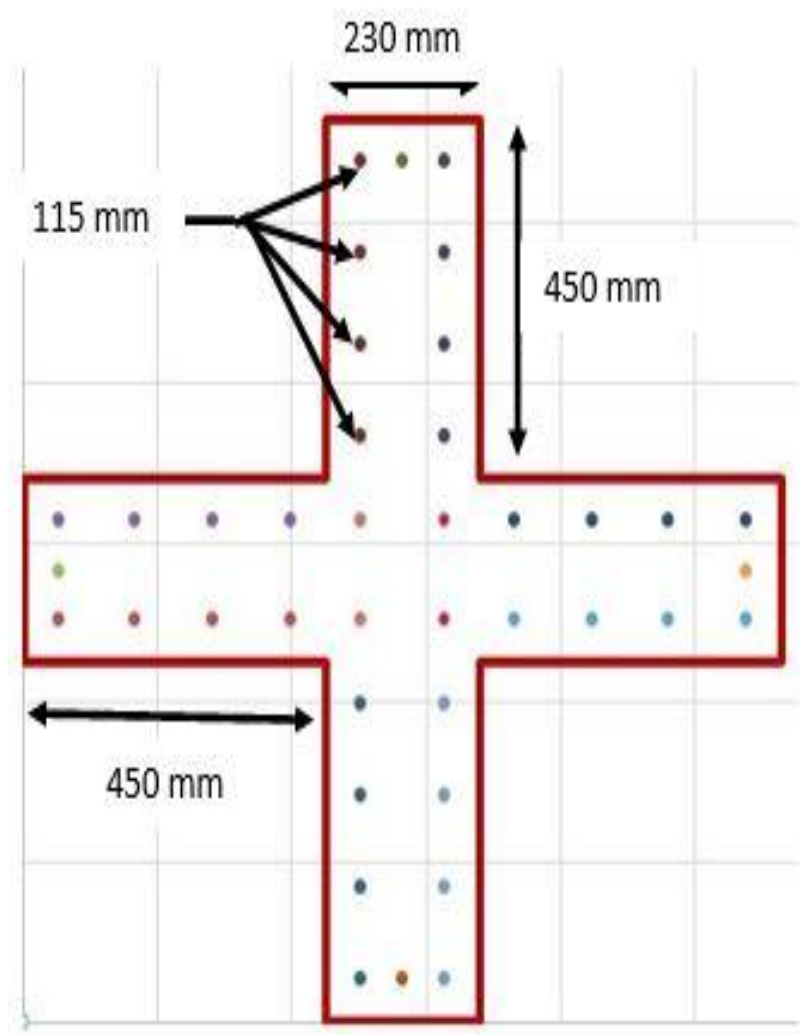

Figure 2: Cross (+) Shaped Column Considered to Study the Influence of Grade of Material

1) For M20 and Fe415 Grades

Problem description

- $\mathrm{f}_{\mathrm{y}}=415 \mathrm{~N} / \mathrm{mm}^{2}$

- $\mathrm{f}_{\mathrm{ck}}=20 \mathrm{~N} / \mathrm{mm}^{2}$

- Reinforcing bar diameter $=20 \mathrm{~mm}$

- $\quad$ Cover $=52.5 \mathrm{~mm}$

Tables for other grades were obtained in a similar fashion

\section{2) For M25 and Fe415 Grades}

Problem description

- $\mathrm{f}_{\mathrm{y}}=415 \mathrm{~N} / \mathrm{mm}^{2}$

- $\mathrm{f}_{\mathrm{ck}}=25 \mathrm{~N} / \mathrm{mm}^{2}$

- Reinforcing bar diameter $=20 \mathrm{~mm}$

- $\quad$ Cover $=52.5 \mathrm{~mm}$ 
Table 3: Load and Moment Capacity for M20 Grade Concrete and $\mathrm{Fe} 415$ Grade Steel

\begin{tabular}{|c|c|c|}
\hline $\begin{array}{l}\text { Reinforcing bar diameter }= \\
\text { 20mmCover }=52.5 \mathrm{~mm} G R A D E\end{array}$ & \multicolumn{2}{|l|}{$M 20$} \\
\hline $\begin{array}{l}\text { DEPTH OF NEUTRAL AXIS 'X }{ }_{U}^{\prime} \\
(\mathrm{mm})\end{array}$ & $\begin{array}{l}\text { LOAD } \\
\text { CAPACITY } \\
(k N)\end{array}$ & $\begin{array}{l}\text { MOMENT } \\
\text { CAPACITY }(k N-m)\end{array}$ \\
\hline$\infty$ (PURE COMPRESSION) & 8172.539746 & 0.0000 \\
\hline 4520 & 8133.521962 & 25.6596 \\
\hline 3390 & 8098.318541 & 44.1905 \\
\hline 2825 & 8063.067919 & 62.0402 \\
\hline 2260 & 7974.297505 & 100.9369 \\
\hline 1695 & 7738.581313 & 200.4655 \\
\hline 1582 & 7650.607614 & 239.0132 \\
\hline 1469 & 7524.598715 & 288.6646 \\
\hline 1356 & 7364.742839 & 354.5701 \\
\hline 1243 & 7133.370285 & 444.3727 \\
\hline 1186.5 & 6982.7615 & 503.7406 \\
\hline 1130 & 6793.530303 & 580.9995 \\
\hline 1077.5 & 6584.561469 & 673.6131 \\
\hline 1020 & 6303.391787 & 776.8466 \\
\hline 962.5 & 5991.295375 & 880.0819 \\
\hline 905 & 5637.741585 & 984.2569 \\
\hline 847.5 & 5236.526123 & 1089.4180 \\
\hline 790 & 4747.586463 & 1195.3955 \\
\hline 732.5 & 4218.132567 & 1294.8840 \\
\hline 680 & 3699.737736 & 1374.1723 \\
\hline 627.5 & 2800.922995 & 1332.9764 \\
\hline 596.25 & 2232.035846 & 1298.0438 \\
\hline 565 & 1651.87415 & 1250.9309 \\
\hline 533.75 & 1042.444571 & 1194.7186 \\
\hline 502.5 & 409.0297406 & 1127.1583 \\
\hline 450 & -751.223467 & 987.0489 \\
\hline 397.5 & -1506.065389 & 940.8042 \\
\hline 340 & -2240.556069 & 866.3968 \\
\hline 282.5 & -2694.779325 & 783.8703 \\
\hline 225 & -3043.522411 & 681.9035 \\
\hline 167.5 & -3363.992302 & 566.8249 \\
\hline 110 & -3693.526634 & 429.6172 \\
\hline 52.5 & -4107.880545 & 221.6753 \\
\hline 0 (PURE TENSION) & -4535.202211 & 0.0000 \\
\hline
\end{tabular}

3) For M30 and Fe415 Grades

Problem Description

- $\mathrm{f}_{\mathrm{y}}=415 \mathrm{~N} / \mathrm{mm}^{2}$

- $\mathrm{f}_{\mathrm{ck}}=30 \mathrm{~N} / \mathrm{mm}^{2} 4$ ) For M35 and Fe415 grades

Problem description

- $\mathrm{f}_{\mathrm{y}}=415 \mathrm{~N} / \mathrm{mm}^{2}$

- $\mathrm{f}_{\mathrm{ck}}=35 \mathrm{~N} / \mathrm{mm}^{2}$

- Reinforcing bar diameter $=20 \mathrm{~mm}$

- $\quad$ Cover $=52.5 \mathrm{~mm}$

4) For M40 and Fe415 Grades

Problem description

- $\mathrm{f}_{\mathrm{y}}=415 \mathrm{~N} / \mathrm{mm}^{2}$

- $\mathrm{f}_{\mathrm{ck}}=40 \mathrm{~N} / \mathrm{mm}^{2}$

- $\quad$ Reinforcing bar diameter $=20 \mathrm{~mm}$

- $\quad$ Cover $=52.5 \mathrm{~mm}$

The interaction diagram has been plotted for these cases considering the various grades of concrete and the graph shows the comparison of load- moment resisting capacities of various grades of concrete for $\mathrm{Fe} 415$ grade steel, the similar calculations were also carried out with Fe 500 grade steel and the interaction diagrams were plotted to study and compare the effect of varying grade of steel also, the results obtained were compared with that of ETABS-2015 and the conclusions were formulated.

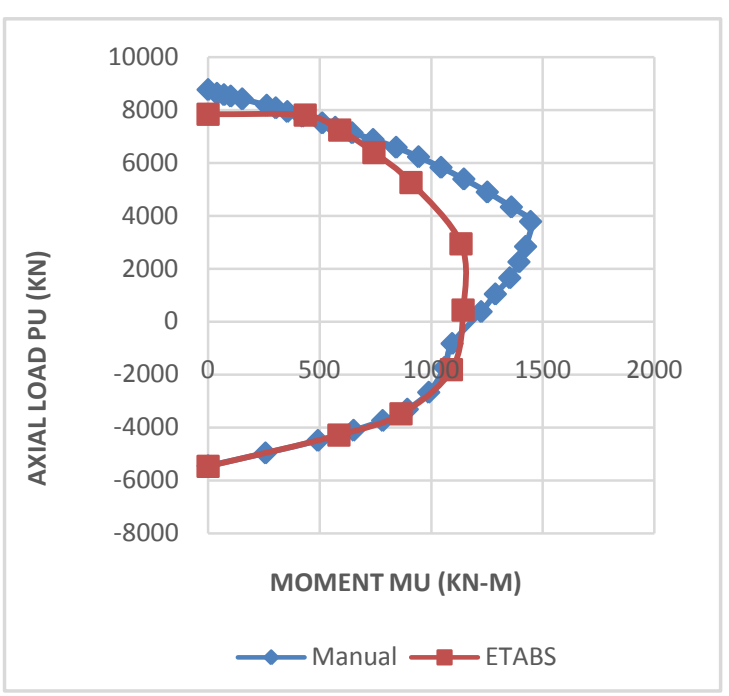

Figure 3: Comparison of Interaction Diagram for M20 Grade of Concrete Obtained from Spread Sheet with that of ETABS for Fe415 Grade Steel

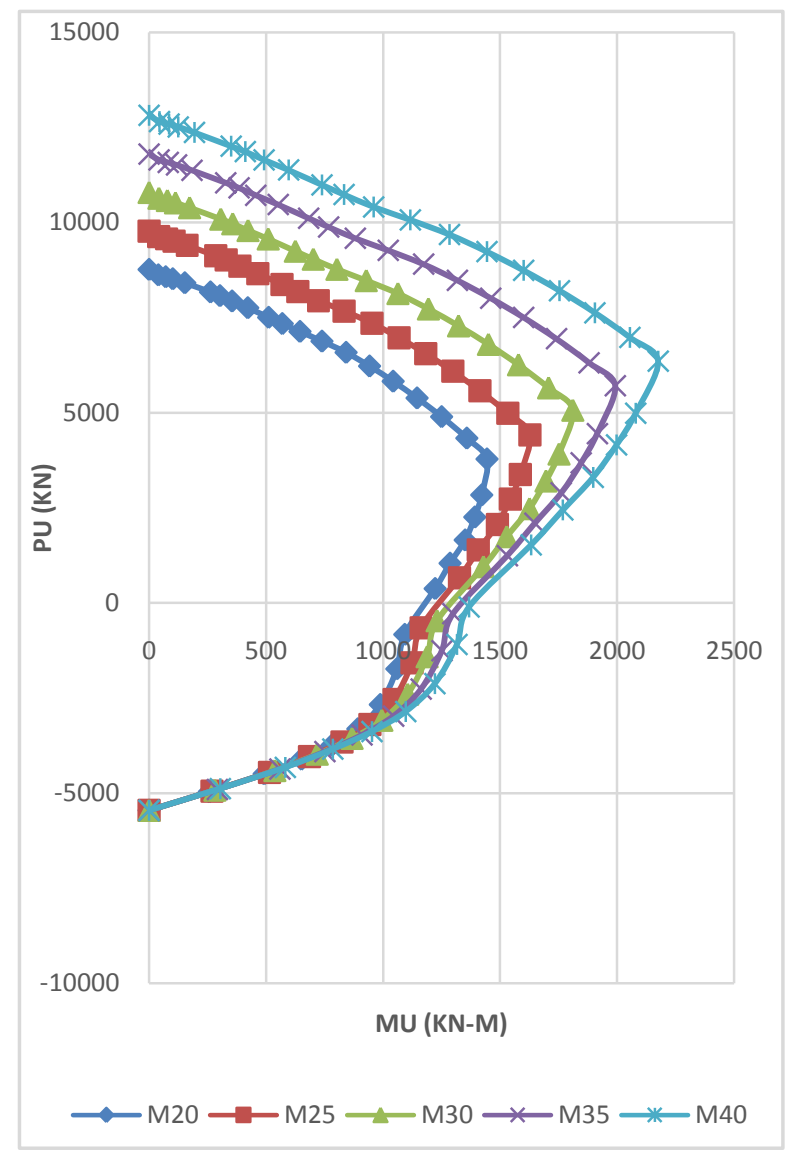

Figure 4: Interaction Diagram for M20, M25, M30, M35 and M40 Grade of Concrete with Fe415 Grade Steel 


\section{B. Influence of Grade of Steel on Strength Characters of Cross (+) Shaped Columns}

Similar calculations were carried out to develop interaction diagrams with Fe500 grade steel and the results were compared with $\mathrm{Fe} 415$ grade steel.

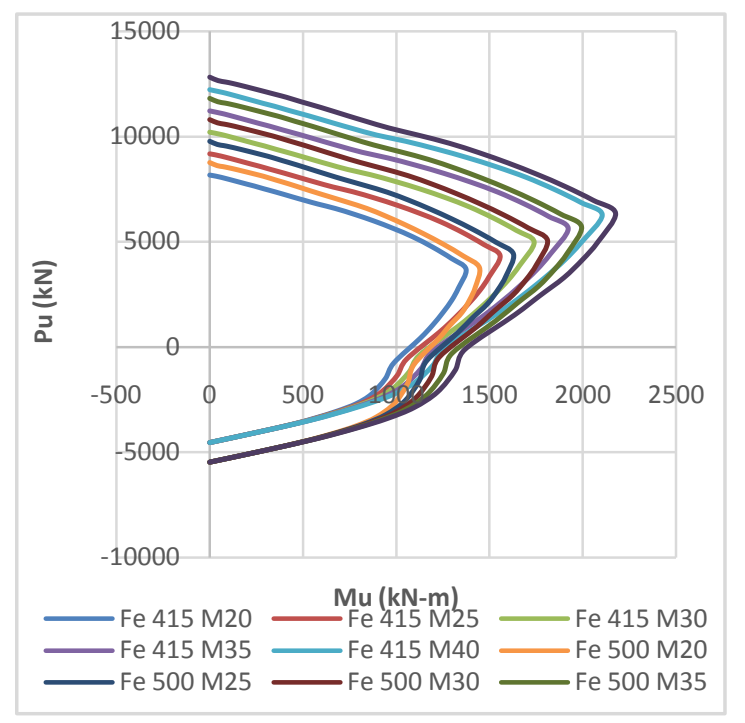

Figure 5: Comparison of Interaction Diagram for $\mathrm{Fe} 415$ and Fe500 Grade of Steel for M20, M25, M30, M35 and M40 Grades of Concrete

C. Influence of Varying Reinforcement Spacing on Strength Characters of Cross (+) Shaped Columns

1. With Constant Spacing for Reference

Problem description

- $\mathrm{f}_{\mathrm{ck}}=20 \mathrm{~N} / \mathrm{mm}^{2}$

- $X$ left overhang $=550 \mathrm{~mm}$ Cover $=52.5 \mathrm{~mm}$

- $X$ right overhang $=550 \mathrm{~mm}$

- $\mathrm{f}_{\mathrm{y}}=415 \mathrm{~N} / \mathrm{mm}^{2}$

- $\quad$ Y top overhang $=550 \mathrm{~mm}$

- $Y$ bottom overhang $=550 \mathrm{~mm}$

- Constant spacing $=148.330 \mathrm{~mm}$

- $\quad$ Cover $=52.5 \mathrm{~mm}$

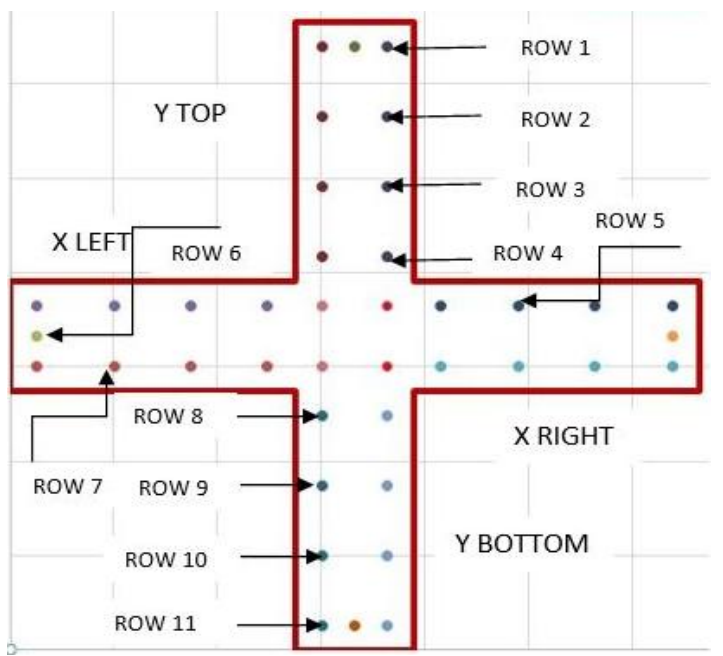

Figure 6: Cross (+) Shaped Column Considered to Study the Influence of Varying Spacing of Reinforcement
2. Spacing between Row 1,2 and between 9,10 Reduced

(Trial 1)

Problem description

- $\quad$ Constant spacing $=148.330 \mathrm{~mm}$

- $\quad$ Reduced spacing $=90 \mathrm{~mm}$

- Other specifications are similar to that of constant spacing case

3. Spacing between row 1, 2, 3 and between 8, 9, 10 reduced(Trial 2)

Problem description

- Constant spacing $=148.330 \mathrm{~mm}$

- $\quad$ Reduced spacing $=90 \mathrm{~mm}$

- Other specifications are similar to that of constant spacing case

4. Spacing between row 1, 2, 3, 4 and between 7, 8, 9, 10 reduced (Trial 3)

Problem description

- $\quad$ Constant spacing $=148.330 \mathrm{~mm}$

- $\quad$ Reduced spacing $=90 \mathrm{~mm}$

- Other specifications are similar to that of constant spacing case

5. Spacing between row 3, 4 and between 7, 8 reduced(Trial 4)

Problem description

- $\quad$ Constant spacing $=148.330 \mathrm{~mm}$

- $\quad$ Reduced spacing $=90 \mathrm{~mm}$

- Other specifications are similar to that of constant spacing case

6. Spacing between row 2, 3, 4and between 6, 7, 8 reduced(Trial 5)

Problem description

- $\quad$ Constant spacing $=148.330 \mathrm{~mm}$

- $\quad$ Reduced spacing $=90 \mathrm{~mm}$

- Other specifications are similar to that of constant spacing case

7. Varying spacing between all rows (Trial 6)

Problem description

- $\quad$ Spacing between row 1 and $2=$ Spacing between row 10 and $11=148.330 \mathrm{~mm}$

- Spacing between row 2 and row $3=$ spacing between row 9 and $10=130 \mathrm{mmCover}=52.5 \mathrm{~mm}$

- $\mathrm{X}$ right overhang $=550 \mathrm{~mm}$

- $\mathrm{f}_{\mathrm{y}}=415 \mathrm{~N} / \mathrm{mm}^{2}$

- $\quad \mathrm{Y}$ top overhang $=550 \mathrm{~mm}$ 


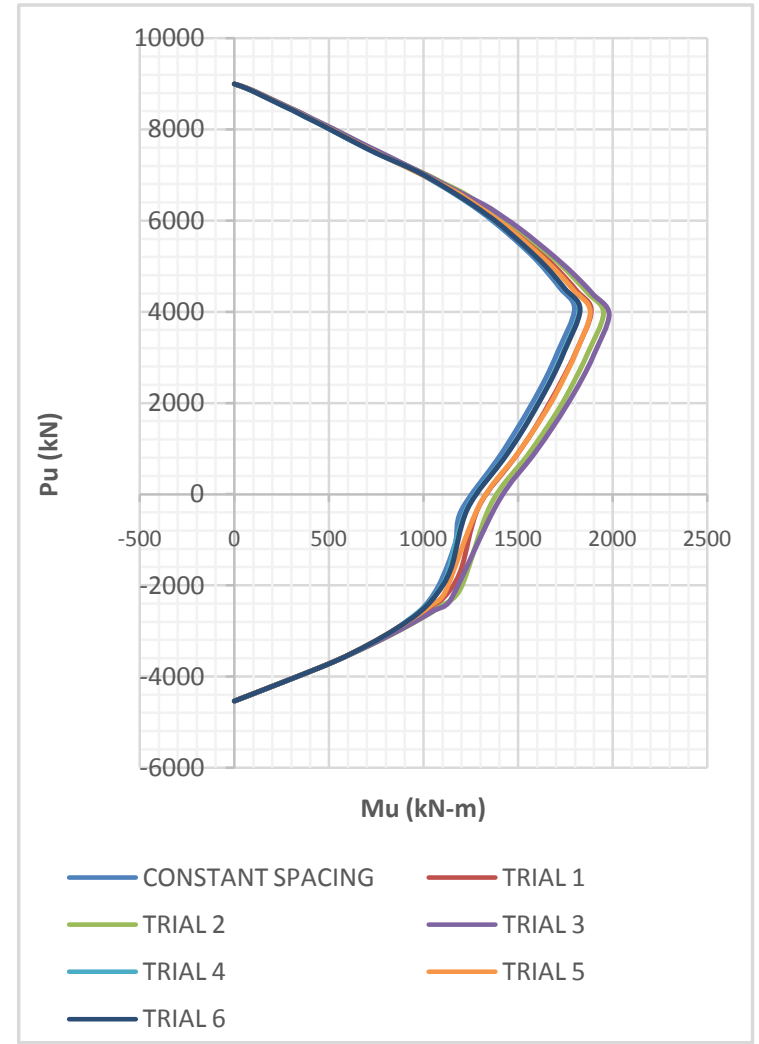

Figure 7: Interaction Diagram for Varying Spacing of Reinforcements

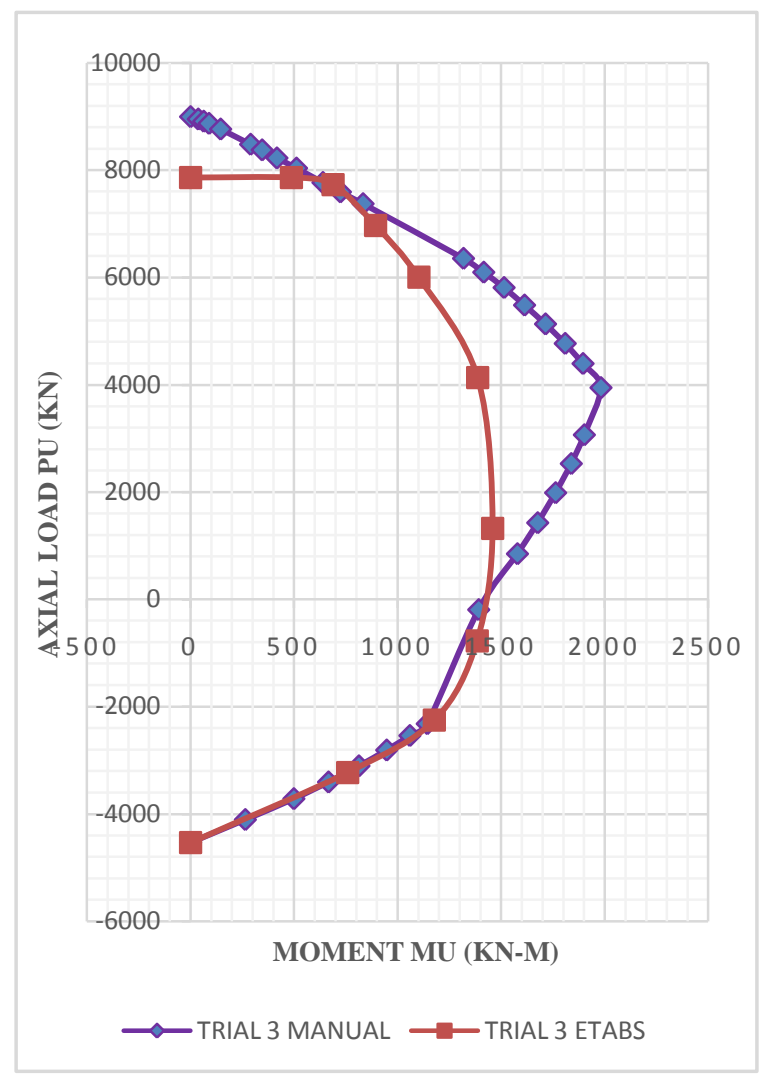

Figure 8: Comparison of Trial 3 of Varying Reinforcement Spacing Results with that of ETABS
For other variable spacing cases table is obtained in a similar fashion, and graphs were plotted as shown in Fig. 7

\section{CONCLUSION}

1. With increase in grade of concrete or grade of steel the maximum load and moment carrying capacity of the cross (+) - shaped column increases.

2. Varying reinforcement spacing will not have any influence on maximum load carrying capacity, but the moment carrying capacity could be effectively increased by varying the spacing of reinforcement compared to constant spacing,

3. Decreasing order of moment carrying capacity with variable reinforcement spacing is trial 3, trial 2, trial 5, trial 6, trial 4, and constant spacing. This demonstrates that if the spacing between reinforcement layers at the outer periphery of legs away from central portion is reduced it results in an increase of moment carrying capacity of the section, and if the spacing between reinforcement layers near the central portion is reduced it results in decreased moment carrying capacity.

4. Comparison of results obtained from spread sheet with that obtained from ETABS has been done the results match well in the tension zone of the interaction diagram but the results of ETABS considerably deviates from manual calculations in compression zone because of consideration of Whitney's stress block parameter in ETABS.

5. A note given in Table $H$ of SP:16 says that for construction of interaction diagram it is sufficient to consider value of $\mathrm{K}$ up to 1.2 only as it corresponds to minimum eccentricity, therefore ETABS considers the interaction up to $1.2 \mathrm{D}$ only but here the interaction diagram from spread sheet has been plotted for the value of $\mathrm{k}=4$, for information therefore there is a deviation from ETABS above minimum eccentricity.

6. Use of cross shaped columns with given percentage of steel can have a higher load and moment resisting capacity compared to that of rectangular sections.

\section{REFERENCES}

[1]. N. Ekta and Kuchhadiya, "computer aided design of reinforced concrete column subjected to axial compression and bending", PARIPEX-Indian journal of research, Vol. 4, No. 5, 2015.

[2]. Dr.S. Sarmad, Abdul-Quader AL-Badri and Dr. Asma'a, A. Ahmad, "Design Charts For Channel Shaped Reinforced Concrete Short Columns Subjected To Axial Compressive Load And Uniaxial Bending", Eng. \& Tech. Journal, Vol. 27, No. 4, 2009.

[3]. L.N. Ramamurthy and T.A. Hafeez Khan, "Journal of Structural Engineering", Vol. 109, No. 8, 1983.

[4]. "IS-456:2000: Indian Standard Code of Practice for Plain and Reinforced Concrete", BIS, New Delhi.

[5]. "SP-16:1980: Design aids for reinforced concrete to IS: 456-1978", Bureau of Indian standards.

[6]. ETABS 2013-Concrete frame design manual IS 456:2000-CSI Computers and Structures INC.

[7]. S.N. Sinha, "Reinforced Concrete Design", Tata McGraw Hill Education private limited New Delhi.

[8]. S.N. Sinha, "Handbook of Reinforced Concrete Design", Tata McGraw Hill education private limited, New Delhi. 1996. 
Table 4: Load and Moment Capacity for Constant Spacing of Reinforcing Bars

\begin{tabular}{|l|l|l|}
\hline $\begin{array}{l}\text { DEPTH OF NEUTRAL } \\
\text { AXIS } X_{U}^{\prime}(\mathrm{mm})\end{array}$ & $\begin{array}{l}\text { LOAD } \\
\text { CAPACITY } \\
(\mathrm{kN})\end{array}$ & $\begin{array}{l}\text { MOMENT } \\
\text { CAPACITY }(\mathrm{kN}-\mathrm{m})\end{array}$ \\
\hline $\begin{array}{l}\infty \text { (PURE } \\
\text { COMPRESSION) }\end{array}$ & 8993.179746 & 0.0000 \\
\hline 5320 & 8950.593473 & 30.9046 \\
\hline 3990 & 8911.816523 & 54.7270 \\
\hline 3325 & 8873.006866 & 77.7570 \\
\hline 2660 & 8774.614424 & 128.0756 \\
\hline 1995 & 8517.662641 & 255.3952 \\
\hline 1862 & 8421.011637 & 305.4095 \\
\hline 1729 & 8281.006244 & 370.0847 \\
\hline 1596 & 8104.794913 & 456.0535 \\
\hline 1463 & 7850.12751 & 573.1465 \\
\hline 1396.5 & 7682.196221 & 651.2376 \\
\hline 1330 & 7470.362036 & 753.5871 \\
\hline 1277.5 & 7281.598434 & 858.3629 \\
\hline 1203.335 & 6971.708502 & 1006.3623 \\
\hline 1129.17 & 6610.251481 & 1153.8180 \\
\hline 1055.005 & 6199.427714 & 1301.2681 \\
\hline 980.84 & 5708.477016 & 1447.7966 \\
\hline 906.675 & 5135.230286 & 1596.6821 \\
\hline 832.51 & 4528.277523 & 1720.5446 \\
\hline 780 & 4055.861956 & 1797.9279 \\
\hline 727.5 & 3139.670573 & 1711.6295 \\
\hline 696.25 & 2566.326878 & 1649.0628 \\
\hline 665 & 1985.871106 & 1573.5235 \\
\hline 633.75 & 1385.452471 & 1487.4782 \\
\hline 602.5 & 761.4632799 & 1390.6192 \\
\hline 550 & -355.3767168 & 1200.0037 \\
\hline 497.5 & -1095.166678 & 1166.1855 \\
\hline 423.335 & -2011.361959 & 1079.3445 \\
\hline 349.17 & -2567.587389 & 979.6099 \\
\hline 275.005 & -2959.734004 & 851.7499 \\
\hline 200.84 & -3307.203875 & 705.6974 \\
\hline 126.675 & -3662.414866 & 531.7352 \\
\hline 52.51 & -4107.880545 & 264.3973 \\
\hline $0($ PURE TENSION) & -4535.202211 & -0.0102 \\
\hline & & \\
\hline & & \\
\hline & &
\end{tabular}

